\title{
Capecitabine/Cisplatin/Trastuzumab Regimen
}

National Cancer Institute

\section{Source}

National Cancer Institute. Capecitabine/Cisplatin/Trastuzumab Regimen. NCI Thesaurus.

Code C160551.

A regimen consisting of capecitabine, cisplatin and trastuzumab that can be used in the treatment of HER-2/neu-positive advanced gastric cancer. 